\title{
MÉTODO SIMPLE PARA RECOLECCIÓN TOTAL DE ORINA DE VACAS EN PASTOREO DE GRAMÍNEAS O ARBUSTIVAS
}

\author{
A SIMPLE DEVICE FOR TOTAL URINE COLLECTION IN BROWSING OR \\ GRAZING COWS
}

\begin{abstract}
Valdivia, V. ${ }^{1}$, Sandoval Castro, C.A. ${ }^{2 \star}$, Otaduy, K. ${ }^{3}$ y Kú Vera, J.C. ${ }^{2 A}$
${ }^{1}$ Universidad Católica del Trópico Seco. Estelí. Nicaragua. viznat1414@yahoo.com.mx

${ }^{2}$ Facultad de Medicina Veterinaria y Zootecnia. Universidad Autónoma de Yucatán. km 15.5. Carretera Mérida-Xmatkuil. Apdo. 4-116. Mérida, Yucatán. México. *ccastro@uady.mx; 'Akvera@uady.mx ${ }^{3}$ Servicio Regional de Investigación y Desarrollo Agroalimentario (SERIDA). Carretera de Oviedo s/n. CP 33300. Villaviciosa, Asturias. España. kosoro@serida.org
\end{abstract}

\section{Palabras clave adicionales}

Bovinos. Silvopastoreo. Metodologías.

\section{RESUMEN}

Se diseñó y evaluó una metodología de recolección total de orina en la hembra bovina en condiciones de silvopastoreo. Para evaluar las bolsas se utilizaron 4 vacas (Bos taurus $\times B$. indicus) con un peso vivo de $415 \mathrm{~kg}$. El tiempo de pastoreo fue de 20 horas/día. La bolsa diseñada funcionó bien y no se observaron pérdidas de orina ni contaminación de la orina con excretas. La excreción de orina por día fue de 12,8; 13,6; 11,97 y $12,3 \mathrm{~kg} / \mathrm{día}$ sin diferencias estadísticas.

\section{SUMMARY}

The design and evaluation of a methodology for total urine collection in browsing and/or grazing cows is presented. The bag was test using 4 cows (Bos taurus $\times$ B. indicus) of $415 \mathrm{~kg} \mathrm{LW}$. Grazing/browsing time was 20 hours/day. The device worked well and without urine loss or contamination with faeces. Urine collection was on average: $12.8,13.6,11.97$ and $12.3 \mathrm{~kg} / \mathrm{d}$ and no significative differences were found.

\section{INTRODUCCIÓN}

Para el estudio de compuestos químicos excretados en la orina se han empleado marcadores como la creatinina o la recolección de muestras mediante sondas o catéteres (Valladares et al., 1999) o arneses

Recibido: 1-9-07. Aceptado: 1-10-07.

\section{AdDitional KEYWORDS}

Cattle. Silvopastoral systems. Methodology.

diversos (Susmel et al., 1994) con resultados variables. Todos estos métodos tienen dificultades al aplicarse en vacas en pastoreo.

El objetivo del presente experimento fue diseñar un método simple para la recolección total de la orina de vacas bajo diferentes condiciones de pastoreo.

\section{MATERIAL Y MÉTODOS}

Se diseñó una bolsa recolectora de orina utilizando caucho procedente de recámaras de neumáticos usados de vehículo. El tubo neumático de 24 cm de diámetro fue cortado a un tamaño de $42 \mathrm{~cm}$ de largo y los extremos fueron vulcanizados dejando en la parte superior un espacio sin vulcanizar para el paso de la válvula de cierre y en la parte inferior derecha de la bolsa otro espacio para ubicar el tubo de drenaje.

La válvula se construyó de tubo de PVC de $1,875 \mathrm{~cm}$ de diámetro y $7 \mathrm{~cm}$ de largo unido a un conector hembra de PVC de 1,875 cm de diámetro, en el extremo libre del conector se puso una esfera móvil de poroplast para realizar la función de cierre del tubo quedando la unidad completa como

Arch. Zootec. 59 (225): 149-152. 2010. 
una válvula funcional. El extremo de la válvula con el conector se ubicó dentro de la bolsa y el otro extremo al embudo conductor, ambas uniones fueron fijadas con abrazaderas (bridas) de 2,5 cm.

El tubo de drenaje se construyó con una sección de tubo de PVC de 1,875 cm de diámetro con un largo de $7 \mathrm{~cm}$ unido en un extremo a un conector macho de 1,875 cm con rosca en un extremo en el cual se colocó un tapón metálico o de PVC. El extremo sin tapón se introdujo dentro de la bolsa y se fijó con abrazadera de 2,5 cm.

La bolsa colectora se fijó a una bolsa de piel sintética que posteriormente se sujetó a un arnés colocado a cada vaca. El arnés es similar a los utilizados para la colección de heces en bovinos en pastoreo pero con algunas modificaciones consistiendo éstas en formar en el arnés un cuadro que pasa alrededor de la vulva de la vaca pasando una faja entre la vulva y el ano y la otra faja a $6 \mathrm{~cm}$ por debajo de la vulva.

Para fijar el embudo colector a la orilla de la vulva se colocó a $5 \mathrm{~cm}$ de la comisura superior un pasador calibre 14 de acero inoxidable de $5 \mathrm{~cm}$ de largo, otro pasador fue colocado a $5 \mathrm{~cm}$ por debajo de la vulva. $\mathrm{La}$ cinta del arnés que pasaba entre la vulva y el ano fue fijado a el embudo conductor con el pasador; esto con el objetivo de evitar contaminación de la orina con excretas. La otra cinta del arnés que pasaba por debajo de la vulva fue fijada al extremo inferior del embudo colector con el pasador ahí ubicado. Los pasadores fueron recolocados perforando sólo la piel 20 días antes de iniciar los muestreos, se lavó el área todos los días para permitir la cicatrización. Los bordes laterales del embudo colector fueron fijados al arnés con hilo de nylon.

Para hacer la prueba de funcionalidad de la bolsa se utilizaron 4 vacas (Bos taurus $\mathrm{x}$ $B$. indicus) con $415 \mathrm{~kg}$ de peso vivo de un experimento contemporáneo las cuales se encontraban en un diseño de cuadro latino repetido 4 x 4 con los siguientes tratamientos. A) Sistema de pastoreo en guinea, B)
Pastoreo asociado a leucaena pero sin acceso a su follaje, C) Silvopastoril (SP) sin suplementación, D) SP suplementado con maíz. Las muestras de orina fueron recolectadas cada cuatro horas, hasta totalizar 24 horas, iniciando a las 6 am durante 5 días consecutivos. La orina fue almacenada y pesada individualmente en bidones con capacidad de 20 litros.

Los datos se realizaron mediante contrastes ortogonales en el procedimiento GLM (SAS, 1996). Los contrastes a comparar fueron:

\section{$\mathrm{C} 1=\mathrm{A} v s . \mathrm{B} ; \mathrm{C} 2=\mathrm{B} v s . \mathrm{C} ; \mathrm{C} 3=\mathrm{C}$ vs. D \\ RESULTADOSYDISCUSIÓN}

Se logró diseñar una bolsa funcional (figuras 1 y 2) para recolección cuantitativa de la orina en vacas en SSP o en otros sistemas de pastoreo.

La excreción de orina por día fue de 12,8; 13,6; 11,97 y 12,3 kg por día \pm 1,71 EEM para los cuatro tratamientos evaluados (Pastoreo guinea; silvopastoril (SP) sin acceso a leucaena; SSP sin suplementación y SP suplementado con maíz respectivamente). No se presentaron diferencias $(p>0,05)$ del tipo de sistema sobre la excreción total de orina por día.

La bolsa permaneció hasta siete días en las vacas (duración de los períodos experimentales) sin ningún problema aparente, tampoco se observó incomodidad del animal. Sin embargo, el primer día de colocación de la bolsa alguna vaca saltaba y pateaba al hacer contacto la bolsa con el corvejón, razón por la cual ese día se dejaba abierto el tubo de drenaje para que no colectara orina y no tuviera peso. Al cabo de un día las vacas ya estuvieron adaptadas al dispositivo y se inicio la recolección de orina.

El dispositivo recolector es más simple que la mayoría de los sistemas recolectores diseñados previamente para la recolecta de orina (Scheineder y Flatt, 1975, Susmel et

Archivos de zootecnia vol. 59, núm. 225, p. 150. 


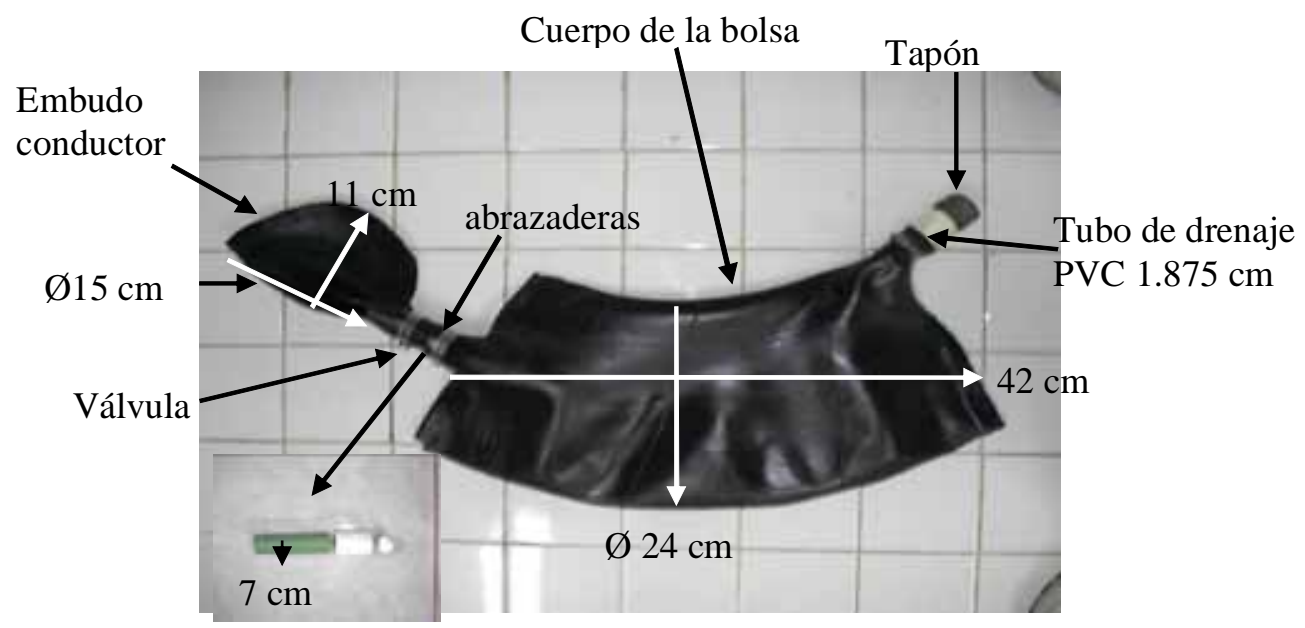

Figura 1. Bolsa recolectora de orina para hembras bovinas. (Urine collecting bag for cows).

al., 1994). El enfoque empleado en el presente trabajo fue realizar colectas de periodos muestreo en momentos predeterminados del día, de manera tal que el dispositivo recolector únicamente retuviera cantidades pequeñas de orina, lo cual simplificó el sistema de sujeción y hace mínimo el riesgo de pérdida de orina (figura 3 ).

En la práctica, un problema que se presenta es la vaca en estro, ya que se recolectan las secreciones procedentes del aparato reproductor, razón por la cual se recomienda desechar la colecta de estos dos días y extender el período de muestreo.
Se recomienda ajustar bien el arnés a la vaca para que soporte bien el peso de la bolsa, si esto no se hace, el peso de la bolsa lo soportan los pasadores y ocasiona desgarre en el punto de fijación. Además se debe reforzar el embudo conductor con un círculo o cuadro de caucho o piel en cada uno de los 4 puntos de fijación.

Al final de los dos últimos períodos de muestreo después que se quitaron las bolsas se notó una ligera inflamación en el área donde se introdujeron los pasadores. En el experimento debido a problemas con la cicatrización, en el período de adaptación se
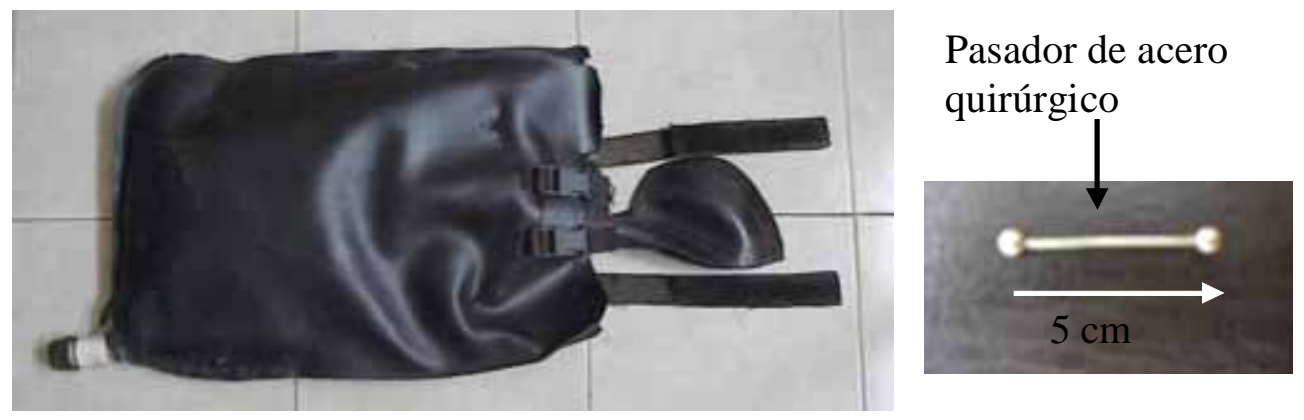

Figura 2. Bolsa colectora fijada a la bolsa de soporte que va sujeta a un arnés. (Collecting bag fixed to supporting bag which will be attached to a harness). 


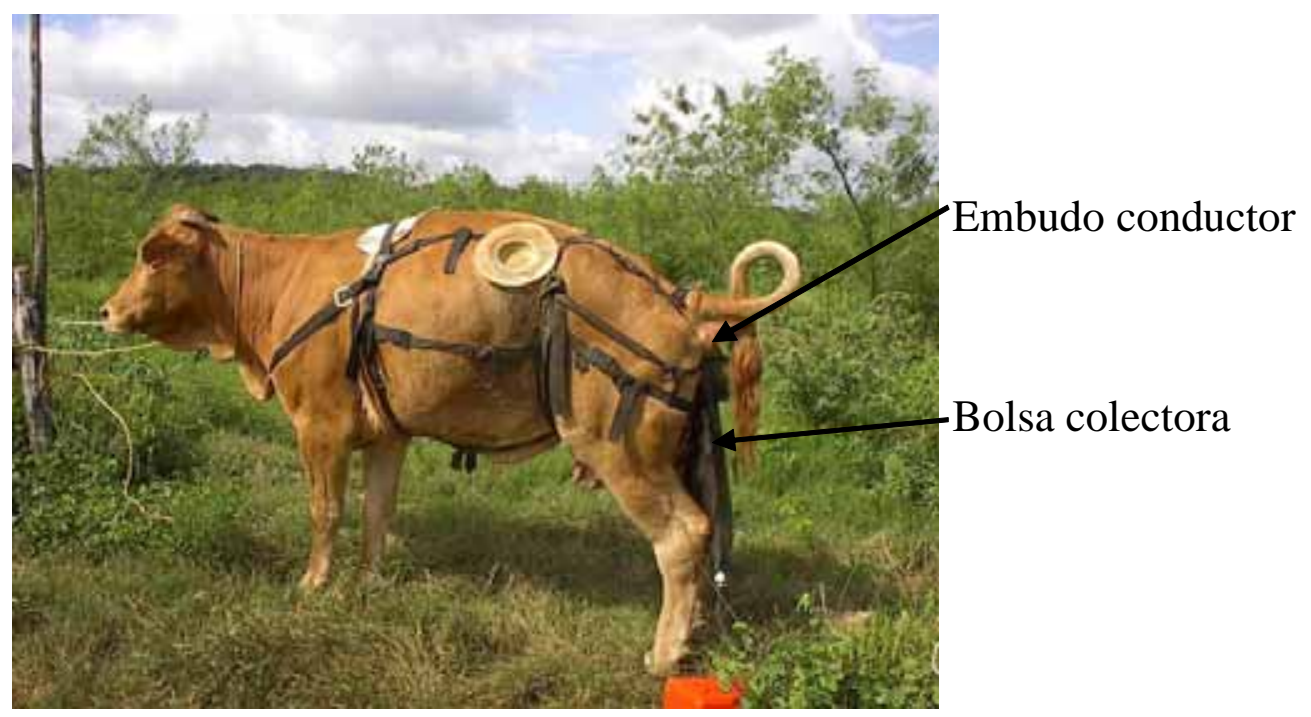

Figura 3. Vaca con la bolsa fijada al arnés. Foto tomada en el momento de la micción. (Cow with the collection bag fixed to the harness. Picture taken when the cow was urinating).

lavó diariamente con yodo la zona donde estaban colocados los pasadores hasta la resolución de la herida. Posterior a esto no se observaron problemas durante el uso de las mismas en experimentos posteriores.

\section{CONCLUSIÓN}

El aparato diseñado permitió la recolección total de orina de vacas bajo diferentes

\section{BIBLIOGRAFÍA}

SAS Institute INC. 1996. SAS/Stat User's guide. Version 6.0 Fourth Edition, Vol 1. SAS Institute Inc. Cary, NC. pp. 943.

Scheineder, B.H. and Flatt, W.P. 1975. The evaluation of feeds through digestibility experiments. The University of Georgia Press. USA. $423 \mathrm{pp}$

Susmel, P., Spanghero, M. and Stefanon, B. 1994. Equipment for separate collection of faeces and condiciones de pastoreo.

\section{AGRADECIMIENTOS}

A la Secretaría de Relaciones Exteriores de México por haber otorgado la beca para realizar estudios de Doctorado. A SAGARPA-CONACYT-Mexico, por la financiación a través del proyecto: 2004C01-110/A-1.

urine for lactating cows: description and variability of data. Zootec. Nutr. Anim., 20: 220236.

Valladares, R.F.D., Broderick, G.A., Valadares Filho, S.C. and Clayton, M.K. 1999. Effect of replacing alfalfa silage with high moisture corn on ruminal protein synthesis estimated from excretion of total purine derivatives. J. Dairy Sci., 82: 2686-2696.

Archivos de zootecnia vol. 59, núm. 225, p. 152. 